\title{
Correlates of Correct HIV Knowledge and Myth Rejection in South Africa: The 2012 National HIV Prevalence, Incidence and Behavior Survey
}

\section{Mabaso $\mathbf{M}^{*}$}

HAST, Human Sciences Research Council, Durban, South Africa

\begin{abstract}
Introduction: Correct knowledge of HIV transmission and prevention and myth rejection is a prerequisite to practicing safer behavior and important for reducing the risk of new infections. This study investigates the association between correct knowledge of HIV transmission, prevention and myth rejection with socio-demographic factors and HIV-related behavioral risk practices in South Africa.

Methods: The study used the 2012 South African national HIV prevalence, incidence and behavior survey data based on a multistage cross-sectional design. Univariate and multivariate logistic regression models were used to examine correlates of correct HIV knowledge and myth rejection.

Results: Of 26,544 sub-sample of youth and adults data (15 years and older) who responded to the HIV knowledge question, only $26.8 \%$ reported correct knowing of HIV transmission, prevention and rejection of all myths about HIV. In the final model significant negative predictors of correct HIV knowledge, prevention and myth rejection included residing in rural informal areas $(\mathrm{OR}=0.68(95 \% \mathrm{Cl}$ : 0.48- 0.95), $\mathrm{p}=0.027)$, and being a harmful alcohol drinker $(\mathrm{OR}=$ $0.18(95 \% \mathrm{Cl}: 0.06-1.29), \mathrm{p}=0.001)$ while sexual debut at 15 years and older $(\mathrm{OR}=1.8(95 \mathrm{Cl}: 1.12-2.91), p=0.015)$ was a significant positive predictor of correct HIV knowledge and myth rejection.

Conclusion: The findings confirms that levels of HIV knowledge can either prevent individuals from making informed choices and take appropriate actions aimed at preventing the infection or make people to take precautions to protect themselves. Efforts to promote HIV knowledge, prevention and myth rejection in the general population should be strengthened given the declining HIV knowledge levels in the country.
\end{abstract}

Keywords: HIV knowledge and myth rejection; Household survey; South Africa

\section{Introduction}

South Africa has the highest burden of HIV globally, and heterosexual intercourse is the predominant mode of HIV infection in the country [1]. The probability of becoming infected depends on the likelihood of unprotected sex with an infected person [2,3]. Different strategies have been implemented to reduce the incidence of HIV in the general population. One of the main objectives of such interventions is to improve the general level of knowledge of HIV with the hypothesis that increasing HIV knowledge will reduce risky behaviors [4,5].

Knowledge about HIV/AIDS is believed to be an important step in HIV-related behaviour change, while low knowledge and misconceptions can prevent individuals from making informed choices and taking appropriate actions aimed at preventing the infection $[6,7]$. It is assumed that people who are knowledgeable about HIV/ AIDS transmission and its prevention are more likely to protect themselves. However, there is limited evidence to show that knowledge is internalised and translated into preventative practices [5]. Empirical evidence gives mixed results about the effect of HIV knowledge on risk behaviour. Some studies show a positive effect of knowledge of HIV and prevention methods on protective sexual behavior [6-8] and others show that having good knowledge is of little protective benefit [9].

In South Africa, findings from the 2012 national HIV survey indicated that there has been a significant decline in accurate knowledge and myths core indicator based on five items on HIV transmission and prevention as recommended by UNAIDS [5] among all age groups from $30.3 \%$ in 2008 to $26.8 \%$ in 2012 [1,4]. Although it is not clear how knowledge impacts HIV-related risk behavior in the country, the 2012 national HIV survey also found that there was a significant decline in condom use at last from 2008 to 2012 [1,4]. This suggests that ignorance about how HIV is transmitted and prevented may be detrimental to HIV prevention efforts. Consequently, there is a need to assess the correct knowledge levels in relation to risk behaviors. This is vital for identifying factors related to knowledge gaps in order to refine implementation of information, education and communication (IEC) activities.

This study investigated the association between correct knowledge of HIV transmission, prevention and myth rejection with sociodemographic factors and HIV-related behavioral risk practices in South Africa.

\section{Methods}

\section{Data}

This study used data from the 2012 South African National HIV Prevalence, Incidence and Behaviour Survey, a nationally representative population-based HIV household survey [1]. Participants were selected

*Corresponding author: Mabaso M, HAST, Human Sciences Research Council, The Atrium, 5th Floor, 430 Peter Mokaba Street, Berea, Durban, South Africa, Tel: 2731242 5608; E-mail mmabaso@hsrc.ac.za

Received February 21, 2018; Accepted March 07, 2018; Published March 14 2018

Citation: Mabaso M (2018) Correlates of Correct HIV Knowledge and Myth Rejection in South Africa: The 2012 National HIV Prevalence, Incidence and Behavior Survey. J AIDS Clin Res 9: 761. doi: 10.4172/2155-6113.1000761

Copyright: (c) 2018 Mabaso M. This is an open-access article distributed under the terms of the Creative Commons Attribution License, which permits unrestricted use, distribution, and reproduction in any medium, provided the original author and source are credited. 
using cross-sectional multi-stage stratified cluster sampling design. A systematic probability sample of 15 households was drawn from each of 1000 enumeration areas (EAs) selected randomly from strata defined by province, locality type and race group province. Institutionalized individuals (including individuals in educational institutions, military barracks, old-age homes, or hospitals) were excluded from the study. In each sampled household all persons residing at the household including visitors who spent a night before were invited to participate. A detailed questionnaire soliciting information related to knowledge, attitudes, practice, behaviours, and demographic factors was administered to participants with informed consent. The current analysis is based on the sub-sample of youth and adults (15 years and older) who responded to the HIV knowledge question only.

\section{Measures}

Dependent variable: The primary outcome is a composite measure defined as correct knowing of transmission and prevention and rejection of all myths about HIV based on the following questions as recommended by UNAIDS [5]:

\section{Can AIDS be cured?}

Can a person reduce the risk of HIV by having fewer sexual partners?

\section{Can a healthy-looking person have HIV?}

Can a person get HIV by sharing food with someone who is infected?

Can a person reduce the risk of getting HIV by using a condom every time he/she has sex?

To create a composite measure the responses were dichotomised into $0=$ incorrect knowledge and $1=$ correct knowledge and myth rejection.

Independent variables: Explanatory variables included sociodemographic variables such as sex (male, female), age groups (15 to 24 years, 25 to 49 years, 50 years and older), race groups (Black African, White, Coloured, Indian/Asian), marital (not married, married) status, educational level (no education/Primary, Secondary, Tertiary), employment status (not employed, employed), and locality type (urban formal, urban informal, rural informal, rural formal). Including HIVrelated risk behaviors such as age at early sexual debut (less than 15 years/more than 15 years), age disparate partnership ( 5 years and older, 5 years and younger, within 5 years older or 5 years younger younger), multiple sexual partners in the last 12 months (one partner, two or more sexual partners), condom use at last sex (no, yes), and alcohol use (abstainers, low risk, hazardous, high harmful, and high risk drinkers) based on the Use Disorder Identification Test (AUDIT) scale [10]. HIV risk perception (no/yes), knowledge of HIV status (yes/no) and actual HIV status were also explore.

\section{Ethical consideration}

Ethical approval for the study was obtained from the Research Ethics Committee of the Human Sciences Research Council, South Africa (REC: 5/17/11/10). The study protocol was also reviewed and cleared by the Associate Director of Science of the National Center for HIV and AIDS, Viral Hepatitis, STD and TB Prevention at the US Centers for Disease Control and Prevention (CDC) in Atlanta, USA.

\section{Statistical analysis}

Descriptive statistics was used summarize socio-demographic profile and HIV-related behavioral practices of the study sample. Chisquare tests were computed to assess differences between categorical variables. Univariate and multivariate logistic regression models were fitted to analyses associations between the primary outcome and a set of socio-demographic and HIV-related variables. Odds Ratio (OR) with $95 \%$ confidence Intervals (CI) and p-value $\leq 0.05$ are reported for factors significantly associated with correct knowledge of HIV transmission, prevention and myth rejection. Analysis was done using STATA 13 (Stata Corp, College Station, Texas, USA) software taking into account the complex multi-level sampling design.

\section{Results}

\section{Background characteristics of the study sample}

Table 1 describes the study sample and correct knowledge of HIV transmission, prevention and myth rejection about HIV by sociodemographic characteristics. Out of a total of 26086 respondents about half were aged $25-49$ years $(50.6 \%)$ and female (51.9\%). The majority of the sample was Black Africans (77.7\%), not married (68.5\%), had secondary level education (70.7\%), was unemployed (61.3\%), and about half leaved in urban formal (52.0\%).

Of 26,544 youths and adults aged 15 years and older who responded to the HIV knowledge question, only $26.8 \%$ reported correct knowing of HIV transmission, prevention and rejection of all myths about HIV. There was no significant difference in correct HIV knowledge and myth rejection between males and females. Correct HIV knowledge and myth rejection was significantly higher among those aged 1524 and 25-49 years compared to those 50 years and older, it was also

\begin{tabular}{|l|c|c|c|c|c|c|}
\hline Variables & Total & $\%$ & \multicolumn{3}{|c|}{ Correct knowledge and myth } \\
\hline Age (years) & & & $\mathbf{n}$ & $\%$ & $95 \%$ CI & p-value \\
\hline 15 to 24 & 7220 & 27.5 & 7154 & 28.6 & $26.8-30.4$ & $<0.001$ \\
\hline 25 to 49 & 11746 & 50.6 & 11634 & 27.7 & $26.0-29.4$ & \\
\hline $50+$ & 7841 & 21.9 & 7756 & 22.4 & $20.5-24.4$ & \\
\hline Sex & & & & & & \\
\hline Male & 48.1 & 11603 & 11464 & 26.2 & $24.6-27.8$ & 0.172 \\
\hline Female & 51.9 & 15203 & 15080 & 27.3 & $25.8-28.9$ & \\
\hline Race groups & & & & & & \\
\hline Black African & 77.7 & 15388 & 15231 & 23.6 & $22.1-25.2$ & $<0.001$ \\
\hline White & 10.3 & 2900 & 2868 & 43.3 & $39.1-47.6$ & \\
\hline Coloured & 9.3 & 4979 & 4942 & 30.3 & $27.4-33.5$ & \\
\hline Indian/Asian & 2.8 & 3467 & 3438 & 41.4 & $37.4-45.5$ & \\
\hline Marital status & & & & & & \\
\hline Not Married & 68.5 & 16878 & 16795 & 25.7 & $24.3-27.2$ & $<0.001$ \\
\hline Married & 31.5 & 9390 & 9342 & 29.3 & $27.4-31.3$ & \\
\hline Education level & & & & & & \\
\hline No education/Primary & 18 & 4351 & 4310 & 19.3 & $17.2-21.6$ & $<0.001$ \\
\hline Secondary & 70.7 & 16112 & 15984 & 27.5 & $26.0-29.0$ & \\
\hline Tertiary & 11.3 & 2288 & 2267 & 40.2 & $36.2-44.4$ & \\
\hline Employment status & & & & & & \\
\hline Not employed & 61.3 & 14426 & 14364 & 24 & $22.6-25.4$ & $<$ \\
\hline Employed & 38.7 & 9779 & 9737 & 31.8 & $29.7-33.9$ & \\
\hline Locality type & & & & & & \\
\hline Urban formal & 52.0 & 15835 & 15686 & 31.7 & $29.6-33.8$ & $<0.001$ \\
\hline Urban informal & 7.8 & 2718 & 2701 & 21.9 & $19.1-25.0$ & \\
\hline Rural informal & 34.7 & 5662 & 5597 & 20.8 & $19.0-22.7$ & \\
\hline Rural formal & 5.5 & 2591 & 2560 & 24.8 & $21.2-28.8$ & \\
\hline Subtotals & & & & & \\
\hline
\end{tabular}

Subtotals do not equal to total $(\mathrm{n})$ due to non-response and / or missing data Table 1: Socio-demographic characteristics of the study sample and correct knowledge of HIV transmission, prevention and myth rejection about HIV. 
significantly higher among other race groups compared Black Africans, those married, those with higher levels of education, the employed and those residing in urban formal areas compared to other settings (all $\mathrm{p}<0.001)$.

Table 2 describes the study sample and correct knowledge of HIV transmission, prevention and myth rejection by HIV-related risk behaviors. Majority of respondents had sexual debut at 15 years and older (93.8\%), had one sexual partner (87.4\%), had sexual partners within 5 years of age $(6.3 \%)$, reported no condom use at last sex $(63.8 \%)$, were abstainers $(61.1 \%)$, perceived themselves as being at risk of HIV infection (76.5\%), about half were not aware of their HIV status (50.2\%) and most were HIV negative (82.9\%). Correct HIV knowledge and myth rejection was significantly higher among participants who reported sexual debut at 15 years or older $(\mathrm{p}<0.001)$, have sexual partner within 5 years older or younger $(\mathrm{p}<0.01)$, self-perceived themselves as at risk of HIV ( $p<0.001)$, low risk alcohol drinkers, and those who had an HIV negative status $(\mathrm{p}<0.05)$.

\section{Factors associated with correct knowledge of HIV and myth rejection}

In the univariate logistic regression analysis (Table 3) correct knowledge of HIV, prevention and myth rejection showed a significant negative association with those 50 years and older $(\mathrm{OR}=0.72(95 \%$

\begin{tabular}{|c|c|c|c|c|c|c|}
\hline \multirow{2}{*}{\begin{tabular}{|l|} 
Variables \\
Sexual debut (age in year) \\
\end{tabular}} & \multirow[t]{2}{*}{ Total } & \multirow[t]{2}{*}{$\%$} & \multicolumn{4}{|c|}{$\begin{array}{c}\text { Correct knowledge and myth } \\
\text { rejection }\end{array}$} \\
\hline & & & $\mathbf{n}$ & $\%$ & $95 \% \mathrm{Cl}$ & p-value \\
\hline$<15$ & 6.2 & 393 & 391 & 18.7 & $14.0-24.5$ & 0.001 \\
\hline$\geq 15$ & 93.8 & 6793 & 6729 & 29.3 & $27.4-31.2$ & \\
\hline \multicolumn{7}{|c|}{ No of sex partners in last 12 months } \\
\hline One partner & 87.4 & 14264 & 14215 & 28.8 & 27.3-30.4 & 0.119 \\
\hline Two partners & 7.2 & 864 & 862 & 27.3 & 23.3-31.7 & \\
\hline More than 2 partners & 5.4 & 630 & 628 & 23.7 & 19.3-28.8 & \\
\hline \multicolumn{7}{|l|}{ Age disparate partnerships } \\
\hline 5 years and older & 20.5 & 3254 & 3243 & 28.2 & 25.6-30.9 & 0.009 \\
\hline 5 years and younger & 19.2 & 2671 & 2662 & 24.9 & $22.3-27.8$ & \\
\hline $\begin{array}{l}\text { Within } 5 \text { years older or } \\
\text { younger }\end{array}$ & 60.3 & 9792 & 9758 & 29.7 & $27.9-31.6$ & \\
\hline \multicolumn{7}{|l|}{ Condom use last sex } \\
\hline No & 63.8 & 10713 & 10676 & 28.7 & $26.9-30.5$ & 0.788 \\
\hline Yes & 36.2 & 4726 & 4710 & 28.3 & $26.2-30.5$ & \\
\hline \multicolumn{7}{|c|}{ Alcohol use risk score (AUDIT*) } \\
\hline Abstainers & 61.1 & 14686 & 14613 & 24.4 & $23.0-25.9$ & $<0.001$ \\
\hline Low risk (1-7) & 27 & 6354 & 6336 & 33.4 & $30.9-35.9$ & \\
\hline Hazardous (8-15) & 9.0 & 1862 & 1852 & 25.7 & $22.7-29.0$ & \\
\hline Harmful (16-19) & 1.5 & 340 & 339 & 21.6 & $15.6-29.2$ & \\
\hline High risk $(20+)$ & 1.4 & 296 & 295 & 26.5 & $19.3-35.2$ & \\
\hline \multicolumn{7}{|c|}{ Perceived risk of HIV infection } \\
\hline No & 23.5 & 4911 & 4891 & 22.3 & 20.3-24.3 & $<0.001$ \\
\hline Yes & 76.5 & 21325 & 21245 & 28.2 & $26.7-29.8$ & \\
\hline \multicolumn{7}{|l|}{ Awareness of HIV status } \\
\hline No & 50.2 & 1276 & 1272 & 24.0 & 20.9-27.5 & 0.403 \\
\hline Yes & 49.8 & 1289 & 1284 & 22.1 & $19.0-25.5$ & \\
\hline \multicolumn{7}{|l|}{ HIV status } \\
\hline Negative & 82.9 & 18075 & 17963 & 25.9 & $24.3-27.5$ & 0.030 \\
\hline Positive & 17.1 & 2632 & 2615 & 23.0 & $20.8-25.4$ & \\
\hline
\end{tabular}

${ }^{*}$ AUDIT Alcohol Use Disorder Identification Test, Subtotals do not equal to total $(n)$ due to non-response and / or missing data

Table 2: Correct knowledge of HIV transmission, prevention and myth rejection about by HIV related risk behaviors.
CI: 0.64-0.81), $\mathrm{p}<0.001)$, those residing in urban informal $(\mathrm{OR}=0.61$ (95\% CI: 0.50-0.74), $\mathrm{p}<0.001$ ), rural informal (OR=0.57 (95\% CI: 0.49 $0.66), \mathrm{p}<0.001)$, rural formal $(\mathrm{OR}=0.71 ; 95 \%$ CI $(0.57-0.89), \mathrm{p}=0.003)$ areas (Table 4). Correct HIV knowledge and myth rejection showed a significant positive association with other race groups (OR=1.96 (95\% CI: 1.72- 2.22), $\mathrm{p}<0.001)$, married participants (OR=1.20 (95\% CI: 1.08 $1.33), \mathrm{p}<0.001)$, those with secondary (OR=1.58 (95\% CI: $1.58-1.58)$, $\mathrm{p}<0.001$, and tertiary education [OR=2.81 (95\% CI: $2.25-3.50) \mathrm{p}<0.001)$ and the employed (OR=1.48 (95\% CI: 1.32-1.65), $\mathrm{p}<0.001$ ).

Furthermore, Table 4 shows that correct knowledge of HIV transmission, prevention and myth rejection about HIV had a significant positive association with those who had sexual debut at 15 years or older age (OR=1.80 (95\% CI: $1.27-2.55), p=0.001)$, sexual partners within 5 years of age than with those with sexual partners 5 years and older $(\mathrm{OR}=1.08$ (95\% CI: 0.92-1.25), $\mathrm{p}<0.001)$, low risk alcohol users ( $\mathrm{OR}=1.55$ (95\% CI: 1.37-1.75), $\mathrm{p}<0.001$ ), and those who perceived themselves being at risk of $\mathrm{HIV}(\mathrm{OR}=1.37$ (95\% CI: 1.21 1.56), $\mathrm{p}<0.001)$. Correct HIV knowledge and myth rejection showed a significant negative association with those with more than 2 partners (OR=0.77 (95\% CI: 0.58-1.00), $\mathrm{p}=0.052$ ), and HIV positive participants (OR=0.86 (95\% CI: 0.74-.98), $\mathrm{p}=0.030$ ).

In the final multivariate model (Figure 1) significant negative predictors of correct HIV knowledge and myth rejection included residing in rural informal areas $(\mathrm{OR}=0.68$ (95\% CI: 0.48- 0.95), $\mathrm{p}=0.027)$, and being a harmful alcohol drinker $(\mathrm{OR}=0.18(95 \% \mathrm{CI}$ : $0.06-1.29), \mathrm{p}=0.001)$ while sexual debut at 15 years and older $(\mathrm{OR}=1.8$ (95 CI: 1.12- 2.91), $\mathrm{p}=0.015$ ) was a significant positive predictor of correct HIV knowledge and myth rejection.

\begin{tabular}{|c|c|c|c|}
\hline Variables & OR & $95 \% \mathrm{Cl}$ & p-value \\
\hline \multicolumn{4}{|l|}{ Age (years) } \\
\hline 15 to 24 & 1 & & \\
\hline 25 to 49 & 0.96 & $0.86-1.06$ & 0.396 \\
\hline $50+$ & 0.72 & $0.64-0.81$ & $<0.001$ \\
\hline \multicolumn{4}{|l|}{ Sex } \\
\hline Male & 1 & & \\
\hline Female & 1.06 & $0.97-1.15$ & 0.172 \\
\hline \multicolumn{4}{|l|}{ Race groups } \\
\hline Black African & 1 & & \\
\hline Other & 1.96 & $1.72-2.22$ & $<0.001$ \\
\hline \multicolumn{4}{|l|}{ Marital status } \\
\hline Not Married & 1 & & \\
\hline Married & 1.20 & $1.08-1.33$ & $<0.001$ \\
\hline \multicolumn{4}{|l|}{ Education level } \\
\hline No education/Primary & 1 & & \\
\hline Secondary & 1.58 & $1.58-1.58$ & $<0.001$ \\
\hline Tertiary & 2.81 & $2.25-3.50$ & $<0.001$ \\
\hline \multicolumn{4}{|l|}{ Employment status } \\
\hline \multicolumn{4}{|l|}{ Not employed } \\
\hline Employed & 1.48 & $1.32-1.65$ & $<0.001$ \\
\hline \multicolumn{4}{|l|}{ Locality type } \\
\hline Urban formal & 1 & & \\
\hline Urban informal & 0.61 & $0.50-0.74$ & $<0.001$ \\
\hline Rural informal & 0.57 & $0.49-0.66$ & $<0.001$ \\
\hline Rural formal & 0.71 & $0.57-0.89$ & 0.003 \\
\hline
\end{tabular}

OR: Odds Ratio, Cl: Confidence Intervals

Table 3: Univariate logistic regression analyses of socio-demographic characteristics associated with correct knowledge of HIV transmission, prevention and myth rejection. 


\begin{tabular}{|l|c|c|c|}
\hline Variables & OR & $95 \%$ Cl & p-value \\
\hline Sexual debut (age in year) & 1 & & \\
\hline$<15$ & 1.80 & $1.27-2.55$ & 0.001 \\
\hline$>=15$ & 1 & & \\
\hline No of sex partners in last 12 months & & & \\
\hline One partner & 0.93 & $0.75-1.15$ & 0.490 \\
\hline Two partners & 0.77 & $0.58-1.00$ & 0.052 \\
\hline More than 2 partners & & & \\
\hline Age disparate partnerships & 1 & & \\
\hline 5 years Older & 0.85 & $0.71-1.01$ & 0.340 \\
\hline 5 years younger & 1.08 & $0.92-1.25$ & $<0.001$ \\
\hline within 5years & & & \\
\hline Condom use at last sex & 1 & & \\
\hline No & 0.98 & $0.87-1.11$ & 0.787 \\
\hline Yes & & & \\
\hline Alcohol use risk score (AUDIT) & 1 & & \\
\hline abstainers & 1.55 & $1.37-1.75$ & $<0.001$ \\
\hline Low risk & 1.07 & $0.89-1.29$ & 0.448 \\
\hline Hazardous level & 0.86 & $0.56-1.29$ & 0.452 \\
\hline Harmful (16-19) & 1.12 & $0.74-1.68$ & 0.597 \\
\hline High risk (20+) & & & \\
\hline Perceived risk of HIV infection & 1 & & \\
\hline No & 1.37 & $1.21-1.56$ & $<0.001$ \\
\hline Yes & & & \\
\hline Awareness of HIV status & 1 & & \\
\hline No & 0.96 & $0.87-1.06$ & 0.416 \\
\hline Yes & 1 & & \\
\hline HIV status & 0.86 & $0.74-.98$ & 0.030 \\
\hline Negative & & & \\
\hline Positive & & \\
\hline OR Odds Rat & & \\
\hline
\end{tabular}

OR: Odds Ratio; Cl: Confidence Intervals; AUDIT Alcohol used Disorder Identification Test

Table 4: Univariate logistic regression analyses of HIV-related risk behaviours associated with correct HIV transmission, prevention and myth rejection.

\section{Discussion}

Correct knowledge about HIV transmission and prevention accompanied by appropriate reduction in behavioural risk practices are important in combating and reversing the spread of HIV [11]. In the current study the socio-demographic profile of individuals with high correct HIV knowledge levels included individuals age (15-24 - and 25-49 years), residing in urban areas, being married, having higher educational qualifications and being employed. Other race groups (White, Coloureds, Indians/Asians) also had higher HIV knowledge levels than Black Africans. HIV-related risk behaviour profile of individuals with high correct knowledge levels included self-reported sexual debut at 15 years or older age, same age sexual partners, self -perceived risk of HIV, low risk alcohol drinking, and negative HIV status.

Studies have shown that younger individuals are more receptive to information and may therefore have higher levels of accurate knowledge about HIV/AIDS [12]. However, others found that that knowledge of HIV transmission and prevention was higher among older age groups [13]. Other studies also found high knowledge levels among those with higher educational level, who were employed, living in urban areas, and were married. This has been attributed to the fact that in many instances higher education can lead to better employment, income and access to information $[14,15]$. Living in urban setting may also have its own advantage in terms of better education and access to information as well as HIV services in general [16]. Given current findings about marital status and knowledge levels it is possible married individuals may be more conscious about the health of their family members and thereby have more knowledge about HIV transmission and prevention.

The univariate analysis found significant positive association with socio-demographic and HIV-related risk profiles of individuals with high knowledge levels and vice versa. Consistent with current findings other studies have also shown that knowledge levels about HIV/AIDS and misconceptions can either prevent individuals from making

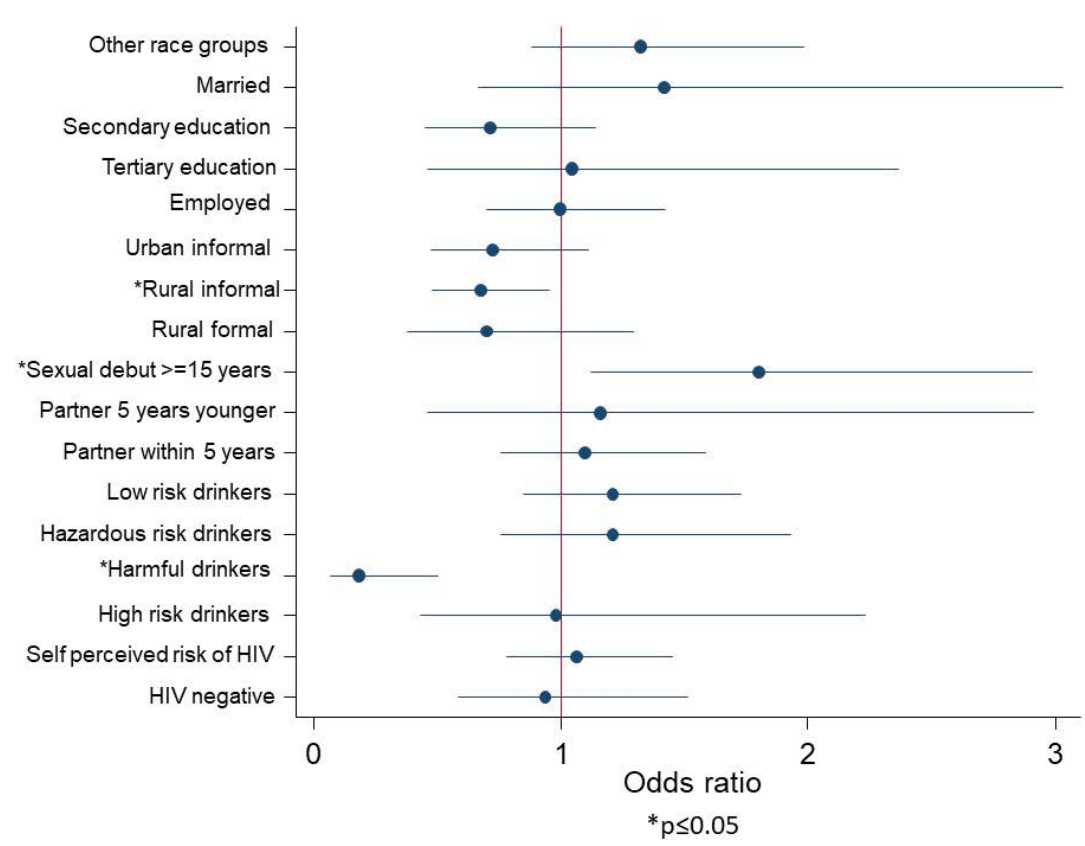

Figure 1: Coefficient plot of the multivariate logistic regression model of factors associated with correct knowledge of HIV transmission, prevention and myth rejection. 
informed choices and take appropriate actions aimed at preventing the infection or make people to take precautions to protect themselves $[17,18]$. However, in the final multivariate model only residing in rural informal areas and high risk/harmful alcohol drinking remained significant negative predictors of correct HIV knowledge and myth rejection while sexual debut at 15 years and older age remained the only significant positive predictor.

Previous studies in rural communities in Africa have indicated that low levels of knowledge and misconceptions about the cause of HIV are widespread [19-21]. This has been attributed to socioeconomic factors such as limited educational opportunities and /or low educational attainment characteristic of rural areas [19,21-23]. This has been shown to lead to risk behaviors that can compromise their sexual health [19-23]. These observations highlight the need for better educational opportunities and for improved information, education and communication (IEC) strategies targeting rural areas in order improve knowledge about HIV transmission and prevention.

In the present study alcohol was the only risk behavior associated with low levels of knowledge about HIV transmission and prevention. Studies show that alcohol use can reduce the ability to learn and to perform sexual risk-reduction strategies [24,25]. It has been observed that despite a high number of participants that engaged in high risk drinking stating that they had been exposed to HIV educational programs, sexual risk behaviors remained high [26]. Therefore, there is a need for HIV risk-reduction strategies, targeting alcohol use in order to improve HIV knowledge in this group and induce behavioral change.

The observed positive association between HIV knowledge and delayed age at sexual debut probably reflects widespread and sustained communication efforts to disseminate messages to motivate people to engage in behavioral change. Evidence show that increased HIV knowledge through comprehensive sexuality education increased among others self-efficacy related to refusing sex, and late initiation of first sexual intercourse [27]. This highlight the importance ageappropriate and culturally relevant comprehensive sexuality education as a strategy to improve HIV knowledge especially among young people [28].

\section{Limitations}

A number of limitations need to be considered when interpreting these results. Since this was a cross-sectional study, causality between the factors analyzed cannot be inferred. Another limitation of this study is recall bias and social desirability bias due to self-report. There may also be other unobserved or unmeasured mechanisms affecting HIV knowledge and myth rejection (positively or negatively). Nevertheless, the strength of this study is the probability-based sampling design that allows us to generalize our results to those aged 15 years and older population in the country. This study therefore provides useful insights on correlates of correct knowing of transmission and prevention and rejection of all myths about HIV in South Africa.

\section{Conclusion}

Generally, higher knowledge levels of HIV transmission, prevention and myth rejection were associated with socio-demographic and behavioral factors synonymous with better access to information. These findings may contribute in the design, targeting, monitoring and evaluation of programs aimed at improving knowledge about HIV transmission and prevention and myth rejection. Efforts towards strengthening and promoting improved HIV knowledge, prevention and myth rejection in the general population should involve evidence-based prevention communication strategies and targeted implementation of social and behavioral interventions [1].

\section{Acknowledgement}

The data used in this article comes from a study supported by the President's Emergency Plan for AIDS Relief (PEPFAR) through the Centers for Disease Control and Prevention (CDC) under the terms of Cooperative Number 3U2GGH000570. The findings and conclusions in this paper are those of the author(s) and do not necessarily represent the official position of the CDC. Additional support was also received from the Bill \& Melinda Gates Foundation, the South African National AIDS Council (SANAC) and the United Nations Children's Fund (UNICEF).

\section{References}

1. Shisana O, Rehle T, Simbayi LC, Zuma K, Jooste S, et al. (2014) South AfricanNational HIV Prevalence, Incidence and Behaviour Survey, 2012. HSRC Press, Cape Town.

2. Morison $L$ (2001) The global epidemiology of HIVIAIDS. British Medical Bulletin 58: 7-18.

3. Weller SC, Davis-Beaty K (2011) Condom effectiveness in reducing heterosexual HIV transmission. Cochrane Collaboration.

4. Shisana O, Rehle T, Simbayi LC, Zuma K, Jooste S, et al. (2009) South African national HIV prevalence, incidence and communication survey 2008: A turning tide among teenagers? HSRC Press, Cape Town.

5. UNAIDS (2013) UNAIDS report on the global AIDS epidemic. Joint United Nations Programme on HIVIAIDS, Geneva.

6. Maclntyre K, Brown L, Sosler S (2001) It's not what you know, but who you knew: Examining the Relationship between Behavior Change and AIDS Mortality in Africa. AIDS Education and Prevention 13: 160-174.

7. Rugigana E, Birungi F, Nzayirambaho M (2015) HIV knowledge and risky sexual behavior among men in Rwanda. Pan African Medical Journal 22: 380.

8. Benefo KD (2010) Determinants of condom use in Zambia: A Multilevel Analysis. Studies in Family Planning 41: 19-30.

9. Williams BG, Taljaard D, Campbell CM, Gouws E, Ndhlovu L, et al. (2003) Changing patterns of knowledge, reported behaviour and sexually transmitted infections in a South African gold mining community. AIDS 17: 2099-2107.

10. Saunders J, Aasland O, Babor T, de la Fuente J, Grant M (1993) Development of the Alcohol Use Disorders Identification Test (AUDIT): WHO Collaborative Project on Early Detection of Persons with Harmful Alcohol Consumption--II. Addiction 88: 791-804

11. UNAIDS (2013) Global AIDS response progress reporting, 2012: Construction of core indicators for monitoring the 2011 UN political declaration of HIVIAIDS. Joint United Nations Programme on HIVIAIDS. Geneva.

12. Agarwal S, Sushma B (2013) Knowledge, attitude and sources of information for increasing awareness about HIVIAIDS among college students. Healthline 4: $50-57$.

13. Wong LP, Chin CKL, Low YW, Jaafar N (2008) HIVIAIDS-Related Knowledge Among Malaysian Young Adults: Findings From a Nationwide Survey. J Int AIDS Soc 10: 148

14. O'Fallon BJL, deGraft-Johnson J, Bisika T, Sulzbach S, Benson A, et al. (2004) Factors Associated with HIVIAIDS Knowledge and Risk Perception in Rural Malawi. AIDS and Behavior 8: 131-140.

15. Rahman MS, Rahman ML (2007) Media and education play a tremendous role in mounting AIDS awareness among married couples in Bangladesh. AIDS Res Ther 4: 10.

16. Bekalu MA, Eggermont S (2013) Media use and HIVIAIDS knowledge: A knowledge gap perspective. Health Promotion International 29: 739-750.

17. Pettifor AE, Rees HV, Kleinschmidt I, Steffenson AE, MacPhail C, et al. (2005) Young people's sexual health in South Africa: HIV prevalence and sexual behaviors from a nationally representative household survey. AIDS 19: 15251534.

18. Agyemang S, Buor D, Tagoe-Darko E (2012) The extent of knowledge about HIVIAIDS among young people in the Ejura-Sekyedumase district of Ghana. J AIDS HIV Res 4: 241-247.

19. National AIDS and STI Control Programme (2008) Kenya AIDS Indicator Survey 2007. Ministry of Health, Nairobi, Kenya. 
Citation: Mabaso M (2018) Correlates of Correct HIV Knowledge and Myth Rejection in South Africa: The 2012 National HIV Prevalence, Incidence and Behavior Survey. J AIDS Clin Res 9: 761. doi: 10.4172/2155-6113.1000761

Page 6 of 6

20. Asefa A, Beyene H (2013) Awareness and knowledge on timing of mother-tochild transmission of HIV among antenatal care attending women in Southern Ethiopia: A cross sectional study. Reproductive Health 10: 66

21. Mwamwenda TS (2014) Education level and (HIVIAIDS knowledge in Kenya. J AIDS HIV Res 6: 28-32.

22. Voeten HA, Egasah OB, Habbema JD (2004) Sexual behaviour is more risky in rural than in urban areas among young women in Nyanza province, Kenya. Sexually Transmitted Diseases 31: 481-487.

23. Shuper P, Neuman M, Kanteres F, Baliunas D, Joharchi N, Rehm J (2010) Casual considerations on alcohol and HIVIAIDS - a systematic review. Alcoho Alcohol 45: 159-166.

24. Simbayi LC, Kalichman SC, Jooste S, Mathiti V, Cain D, et al. (2004) Alcohol use and sexual risks for HIV infection among men and women receiving sexually transmitted infection clinic services in Cape Town. South Africa. J Stud Alcohol 65: 434-442.

25. Shuper P, Neuman M, Kanteres F, Baliunas D, Joharchi N, et at. (2010) Casual considerations on alcohol and HIVIAIDS - a systematic review. Alcohol Alcohol 45: 159-166.

26. Schwitters A, Sabatier J, Seth P, Glenshaw M, Remmert D, et al. (2015) HIV and alcohol knowledge, self-perceived risk for HIV, and risky sexual behavior among young HIV-negative men identified as harmful or hazardous drinkers in Katutura, Namibia. BMC Public Health 15: 1182.

27. Fonner VA, Armstrong KS, Kennedy CE, O'Reilly KR, Sweat MD (2014) School Based Sex Education and HIV Prevention in Low- and Middle-Income Countries: A Systematic Review and Meta-Analysis. PLoS ONE 9: e89692.

28. UNESCO (2015) Emerging evidence, lessons learned and practices in comprehensive sexual education. Paris, UNESCO. 